\title{
Effects of social deprivation and familiarity with the environment on social attraction in rats*
}

\author{
BIBB LATANÉ and DAVID WALTON \\ Ohio State University, Columbus, Ohio 43210
}

Rats housed alone or with another rat were either given individual preexposure to an open-field testing situation or not. Rats were then observed in pairs for 8 days, and measures were taken of social attraction. As in previous studies, familiarity with the open field, whether achieved through individual preexposure or continued testing in pairs, strongly increased social attraction for socially deprived animals. Double-housed animals, however, as predicted, showed little effect of familiarity. In a familiar open field, single-housed rats were much more affiliative than socially satiated rats. Measures of emotionality suggest that greater responsiveness of isolated rats both to their environment and to their partner, not fear, is responsible for the pattern of results.

One of the most consistent findings of recent investigations into the social behavior of rats has been that rats housed alone and deprived of social contact are more gregarious when given the opportunity than rats housed in pairs. Although on the first day or two of testing differences between housing conditions are small, with repeated testing, strong experimental effects appear (Cappell \& Latané, 1969; Latané, Cappell, \& Joy, 1970; Latané, Schneider, Waring, \& Zweigenhaft, 1971; Latané, Poor, \& Sloan, 1972; Walton \& Latané, 1972). The effects are shown in a statistical interaction such that single-housed animals typically show a strong increase in gregariousness with repeated testing, while double-housed rats show little or no increase.

Increased gregariousness with increased testing has been found in a number of other experiments using single-housed rats (e.g., Latané, 1969; Latané \& Glass, 1968; Latané \& Werner, 1971). Eckman, Meltzer, \& Latané (1969) suggested that the effects of day of testing could best be explained as resulting from increased familiarity with the open field rather than increased familiarity with other rats. They suggested that in an unfamiliar field, rats may be deterred from engaging in social interaction by fear or by being distracted by the desire to explore. As rats become more familiar with the field, these competing motives drop out, leaving more time for sociability.

In order to test this line of thought, Eckman, Meltzer, and Latané gave some rats 6 days of individual

* This research was supported in part by Grants GS2292 and GS27340 from the National Science Foundation. Request reprints from Bibb Latané, 404C West 17 th Ave., Columbus, Ohio 43210 . preexposure to the field before the start of testing. As expected, on the first day of testing, these rats were much more gregarious than nonexposed rats and, unlike nonexposed rats, showed no increase in gregariousness over days. In a second experiment, Eckman, Meltzer, and Latane switched animals from a familiar to a strange open field and found a significant decrease in gregariousness.

Following this pattern of results, the consistent Housing by Days interaction found in many studies would seem to suggest that group-housed animals, which do not show large days effects, are not as deterred by fear or exploration from engaging in social interaction in an unfamiliar field as are socially isolated animals. If this were so, we should expect that group-housed animals would not benefit as much from prior exposure to the open field as do single-housed rats. This experiment was designed to test this line of thought by housing animals either singly or in pairs and by allowing some to gain individual preexperience with the open field before testing in pairs for gregariousness. We expected to find large increases in attraction over days only for single-housed non-preexposed rats.

SUBJECTS AND APPARATUS

Sixty-eight male experimentally naive 240 -day-old albino rats (Sprague-Dawley strain), maintained on an ad lib food and water schedule, had come to the laboratory at the age of 30 days and had been kept in standard double cages $(17 \times 10 \times 7$ in. with a wire mesh front and bottom) in groups of four to six. Animals were observed in a 4-ft-diam circular open field marked off into 49 approximately equal areas (Latané, 1969). The field was illuminated by a
40-W light bulb in a conical shield which directed the light into the open field.

\section{HOUSING AND EXPERIMENTAL} CONDITIONS

Animals were randomly housed either in pairs in double cages (38 animals) or alone in single cages ( $8 \mathrm{x}$ $10 \times 7$ in., 30 animals). Twenty double-housed rats (10 pairs) and 16 single-housed animals (8 pairs) were given individual preexposure to the open field, while 9 double-housed pairs and 7 single-housed pairs did not receive preexposure. ${ }^{1}$ PROCEDURE

After 7 days of differential housing, animals in the preexposure conditions were placed individually in an open field and allowed freely to run about and explore for 5 min each day for 6 days. Thirteen days after housing assignments (7 days in housing condition plus 6 days of preexposure), all animals were tested in the open field in pairs for the first time. Each pair was observed for $5 \mathrm{~min}$ a day for 8 days. The 8 -day analysis allowed us to compare the effects of running in the open field in pairs with the effects of being alone in the open field for an equal amount of time. Preexposed animals tested in pairs on Days 1 and 2 had spent as much time in the open field as non-preexposed animals on Days 7 and 8 . Animals were tested with the same partner, a noncagemate from their own experimental condition, throughout the experiment. DEPENDENT MEASURES

During each $5+\mathrm{min}$ experimental period, measures were taken of amount of time in contact and the location of each animal was recorded at $10-\mathrm{sec}$ intervals. Time in contact was counted whenever the two rats were in direct physical contact, including vibrissae but excluding tail-to-tail contact. At the end of each session, fecal boluses were counted and the field cleaned with a damp sponge soaked in a vinegar and soap solution to eliminate any odors from the previous pair. An immobility measure for each rat was derived from its recorded locations by counting the number of 10 -sec intervals during which it did not change location. \section{RESULTS}

Time in Contact

The obtained pattern of results conformed nicely to predictions (Fig. 1). As in previous experiments, single-housed non-preexposed animals showed a significant increase in social contact over days of testing, from $36 \%$ on Days 1 and 2 to $60 \%$ on Days 7 and $8(\mathrm{~F}=13.4, \mathrm{df}=1,14, \mathrm{p}<.005) .{ }^{2}$ An overall analysis of variance on contact scores for Days 1 and 2 vs Days 7 and 8 showed that, as predicted, this increase was significantly larger than 
that for animals from all other cells (interaction $F=11.8, \quad d f=1,30$, p < .005). A significant main effect for housing $(F=16.2, \quad \mathrm{df}=1,30$, $\mathrm{p}<.001$ ), a marginally significant increase over days $(F=3.90$, $\mathrm{df}=1,30, \mathrm{p}<.06$ ), and a significant Exposure by Days interaction $(\mathrm{F}=9.13, \mathrm{df}=1,30, \mathrm{p}<.01)$ were also found. In order to understand these results more fully, simple effects analyses were performed.

Considering only non-preexposed animals, there were significant effects of housing ( $F=5.08, \quad d f=1,14$, $\mathrm{p}<.05)$, days $(\mathrm{F}=12.0, \mathrm{df}=1,14$, $\mathrm{p}<.005$ ), and a marginal Housing by Days interaction $(F=4.13, d f=1,14$, $p<.07)$. Socially deprived rats significantly increased contact by $24 \%$ between the first 2 and last 2 days. Socially satiated rats showed only a nonsignificant $6 \%$ increase $(F=1.6$, $\mathrm{df}=1,14$, n.s.). The pattern of results for these non-preexposed animals was identical to that found in previous experiments; the marginality of the interaction was probably due to the relatively small $n$.

The results of the Eckman, Meltzer, and Latané study were also replicated. Considering only single-housed animals, there was a main effect of days $(F=6.62$, $\mathrm{df}=1,13, p<.03)$ and a significant Exposure by Days interaction $(F=10.0, d f=1,13$, $\mathrm{p}<.01$ ). Preexposure completely eliminated the increase in contact over days shown by nonexposed rats ( $F=0.19, \mathrm{df}=1,13, \mathrm{n}$.s.). Preexposed animals on Days 1 and 2 (after 6 days of individual exposure to the field) spent $56 \%$ time in contact and did not differ significantly from nonexposed rats on Days 7 and 8 (after 6 days of exposure in pairs to the field), which spent $60 \%$ time in contact $(F=0.09$, df $=1,13$, ns.).

Rats in the preexposed conditions showed a significant housing effect $(F=12.6, \mathrm{df}=1,16, \mathrm{p}<.005)$ but no differences due to days or the Housing by Days interaction. Finally, as expected, double-housed rats were not affected by preexposure to the field, days, or the interaction of exposure with days.

\section{Boluses and Immobility}

Rats defecated infrequently, averaging only .6 boluses per rat per day. There were no significant differences among conditions. Preexposed rats were somewhat less immobile than non-preexposed animals, being immobile for only $13.5 \%$ vs $21 \%$ of the 10 sec intervals ( $F=2.31, \mathrm{df}=1,30, \mathrm{p}<.14$ ). Housing did not affect immobility.

\section{DISCUSSION}

Socially deprived rats were more sociable than socially satiated rats-but only if they had become familiar with

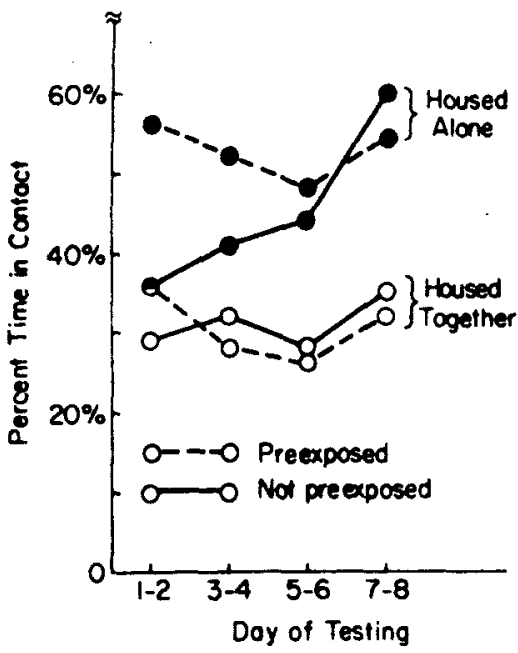

were individually preexposed to the open field were as gregarious on the first days of testing in pairs as non-preexposed rats tested 6 days later. The only other experiment which manipulated preexposure showed similar results (Eckman, Meltzer, \& Latané, 1969). Both experiments support the conclusion that the gradual increase in gregariousness over days typically shown by socially isolated rats reflects increasing familiarity with the open field rather than increasing social deprivation or increasing familiarity with a testing partner.

Although socially deprived rats typically show strong increases in sociability over days, there is no strong corresponding increase for double-housed animals who are socially satiated. Why not? One possibility is that socially deprived animals are more emotional and fearful than socially satiated animals (Ader, Kreutner, \& Jacobs, 1963; Latané, Cappell, \& Joy, 1970) and thus are initially more inhibited in an unfamiliar testing situation. However, socially deprived animals in the present experiment did not differ from double-housed animals on either the bolus or immobility measures.

Another possibility is that socially deprived animals are more responsive to their environment than socially satiated animals (Glanzer, 1953; Premack, Collier, \& Roberts, 1957). If so, we would expect them to be more influenced both by the field and by their partners. At first, responsiveness to the unfamiliar field would compete with responsiveness to the partner, leading socially deprived rats to be no more sociable than double-housed animals. As the novelty of the field wore off, greater social responsiveness would begin to manifest itself.

\section{REFERENCES}

strong tendency to become more affiliative over days, while doubled-housed animals tend to show little increase (Latané, Schneider, Waring, \& Zweigenhaft, 1971; Latanê, Cappell, \& Joy, 1970; the present experiment). One explanation of this effect could be that as the social deprivation of single-housed animals increases over days of differential housing, it has increasingly strong effects. However, similar effects occur in experiments in which testing starts after different amounts of deprivation. Single-housed animals have shown increasing gregariousness over days in tests starting as many as 40 days (Latané, Cappell, \& Joy, 1970) and as few as 2 days (Latané, Nesbitt, Eckman, \& Rodin, in press) after the start of social deprivation.

Familiarity with the field seems to be a better explanation of the days effect. Socially deprived animals who
ADER, R., KREUTNER, A., \& JACOBS, H. $L$. Social environment, emotionality and alloxan diabetes in the rat. Psychosomatic Medicine, 1963, 25, 60-68.

CAPPELL, H., \& LATANE, B. Effects of alcohol and caffeine on the social and emotional behavior of the rat. Quarterly Journal of Studies on Alcohol, 1969, 30, 345-356. LATANE, B. Gregariousness in rats as a function of familiarity of environment. Journal of Personality \& Social Psychology, 1969, 11, 107-114.

GLANZER, $M$. The role of stimulus satiation in spontaneous alternation. Journal of Experimental Psychology, $1953,45,387-393$.

LATANÉ, B. Gregariousness and fear in laboratory rats. Journal of Experimental Social Psychology, 1969, 5, 61-69.

LATANE, B., CAPPELL, H., \& JOY, $V$. Social deprivation, housing density, and gregariousness in rats. Journal of Comparative \& Physiological Psychology, $1970,70,221-227$.

LAT ANÉ, B., \& GLASS, D. C. Social and nonsocial attraction in rats. Journal of
ECKMAN, J., MELTZER, J. D., \& 
Personality \& Social Psychology, 1968, 9, 142-146.

LATANE, B., NESBITT, P., ECKMAN, J. \& RODIN, J. Long- and short-term social deprivation and sociability in rats. Journal of Comparative \& Physiological Psychology, in press.

LATANE, B., POOR, D., \& SLOAN, L Familiarity and attraction to social and nonsocial objects by rats. Psychonomic Seience, 1972, 26, 171-172.

LATANE, B., SCHNEIDER, E., WARING,
P., \& ZWEIGENHAFT, $R$. The specificit of social attraction in rats. Psychonomi Science, 1971, 23, 28-29.

LATANÉ, B., \& WERNER, C. Social and nonsocial sources of attraction in rats. Psy chonomic Science, 1971, 24, 147-148.

PREMACK, D., COLLIE R, G., \& ROBERTS, C. L. Frequency of light contingent bar pressing in rats as a function of the amount of stimulus dependency. American Psychologist, $1957,12,411$.
WALTON, D, \& IATANÉ, B, Visual vS physical social deprivation and affiliation in rats. Psychonomic Science, 1972, 26 , 4-6. NOTES

1. Uneven ns per condition resulted from a shortage of single cages and from injury to one animal in the single nonpreexposed condition.

2. All significance levels are based on two-tailed analysis of variance scores on Days 1-2 and 7-8.

\section{ERRATUM}

TARTE, ROBERT D., and SNYDER, RON L. Barpressing in the presence of free food as a function of food deprivation. Vol. 26, pp. 169-170-Page 169, col. 3 , line 6 , sentence should read: Group 3 was deprived for $24 \mathrm{~h}$ and Groups 4 through 7 were deprived for 36,48 , 72 , and $92 \mathrm{~h}$, respectively, before the experimental session. 